\title{
A Clarion Call for More Qualitative Studies in Surgery
}

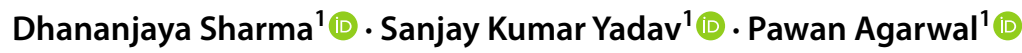

Received: 24 May 2021 / Accepted: 24 June 2021 /Published online: 5 July 2021

(c) Association of Surgeons of India 2021

\begin{abstract}
Qualitative studies in Surgery are important because they contextualize the previously missing social facets of the surgical narrative and inquire into the crucial issues of quality of life/well-being, gender and other discriminations and biases faced by surgeons and patients, surgical education/training, mental issues and burnout, etc. This has resulted in an increasing trend of qualitative studies in surgery. Authors, editors and journals have to ensure that the principles of scientific rigour in qualitative research are followed; otherwise, the answers will not be valid, thus rendering the whole exercise futile. More studies, addressing these fascinating 'social' facets of surgery, are needed.
\end{abstract}

Keywords Qualitative studies · Surgery · Applied social science

Qualitative studies started making their appearance in the medical literature around the time the revolution of Evidence-Based Medicine was taking the Medical World by storm. Not surprisingly, these were labelled as anecdotal, unscientific social/anthropological studies and for a long time, the gatekeepers of medical science, the editors of influential journals, gave them low priority [1]. It took persistent efforts by committed researchers to convince them that qualitative studies are important and actually complement the conventional quantitative studies in medical research [2]. As the surgical scientists introspected and reflected on their purpose, they realized that qualitative studies allow them to go beyond the numbers and contextualize the previously missing social facets of the surgical narrative - from the point of view of both the patient and the surgeon. This newly found awareness has prompted increasing use of qualitative methods in surgery to inquire into the crucial issues of quality of life/well-being, gender and other discriminations and biases faced by surgeons and patients, surgical education/training, mental issues and burnout, etc. [3-9]. As the

Dhananjaya Sharma

dhanshar@gmail.com

Sanjay Kumar Yadav

sky1508@gmail.com

Pawan Agarwal

drpawanagarwal@yahoo.com

1 Department of Surgery, NSCB Government Medical College, Jabalpur, MP 482003, India surgical qualitative literature continues to grow, these social/ anthropological phrases and issues have become ingrained in surgical lexicon and ethos. The resulting increasing trend of qualitative studies in surgery can be seen in Table 1.

Broadly speaking, qualitative surgical studies aim to understand specific behaviour, behaviour change or barriers to change; meaning of and reasons behind such behaviours; understanding the meaning of concepts such as pain, illness, patient satisfaction, quality of care, quality of life and autonomy in a specific group; capturing perceptions of a population on specific products or interventions; process documentation or evaluation of interventions; and situational analysis, etc. [10]. It must be remembered that sampling, data collection and analysis are different in qualitative studies. While qualitative surgical studies can be concluded relatively quickly, their limitations include lack of funding and trained qualitative researchers at the grass-roots. And if done selectively, the researcher may misinterpret and try to quantify the outcome and then the results may be disconnected from its broader context [10]. However, the principles of scientific rigour in qualitative research are well known and if followed, such pitfalls can be avoided [11, 12].

Qualitative research has to have a face validity and trustworthiness; otherwise, it may not clear the bar of needed scientific rigour. A simple example is triangulation of surgeon's observation on clinical/functional outcome measured by clinical score, when supplemented by laboratory data and patient's feedback completes a qualitative study [13]. Since every data can have some weakness or bias, triangulation 
Table 1 Number of published qualitative surgical studies in PubMed since 2005

\begin{tabular}{lllll}
\hline Key word searched* & $2005-2009$ & $2010-2014$ & $2015-2019$ & $\begin{array}{l}2020- \\
\text { May 21 } \\
2021\end{array}$ \\
\hline Quality of life/well being & 633 & 2332 & 4387 & 2677 \\
Surgical education/training & 118 & 246 & 309 & 129 \\
Gender discrimination & 6 & 16 & 54 & 28 \\
Mental health & 4 & 49 & 172 & 82 \\
Racial and ethnic Discrimination & 4 & 11 & 36 & 13 \\
Burn out & 2 & 7 & 44 & 31 \\
\hline
\end{tabular}

${ }^{*}$ Combined with $<$ Surgery $>$ and $<$ Qualitative study $>$ as cross-checking can strengthen the quality of evidence and validity through the convergence of information from different sources. Qualitative research at times yields much higher dividends than quantitative research. Use of openended questions allows respondents to include more information, including feelings and understanding of the subject. This allows researchers to better access the respondents' true feelings on an issue and more deeply understand the topic under discussion, which can be infinitely more than what can be accessed from a qualitative study.

As the acceptance of such studies gained, as with other types of studies, standards for reporting qualitative research were formulated for helping the authors during manuscript preparation, and editors and reviewers in evaluating a manuscript [14]. The next logical step was advice on 'how to read surgical qualitative studies' as the surgeons must be familiar with the basic techniques for the critical appraisal of qualitative studies in the surgical literature [15]. It must be remembered that this gaining popularity may be short-lived and readers may get disenchanted if the issues addressed are not important for them or if the studies are of poor quality - something the authors, editors and journals have to watch out for [16]. A prominent example is surfeit of internet-based questionnaires eliciting qualitative information on various topics. Unless the questionnaire is appropriately designed, the answers will not be valid, thus rendering the whole exercise futile [17]. These studies not only address weighty and salient issues like QOL, discriminations, biases and burnouts affecting the surgical ecosystem; but more importantly, they have prompted much needed remedial reforms to mitigate these issues. However, continuous follow-up research is crucial to ensure these visible gains are not fallacious, as overt acts of discrimination brought under the society's lens may continue covertly [18-20].

Late Rudolf Ludwig Carl Virchow (1821-1902), widely considered as 'the father of modern pathology', was also the 'founder of social medicine'. If his teachings were remembered, the fact that 'medicine is a social science' would never have been questioned [21]. Applied social science in the form of qualitative studies in Surgery has come a long way since the early days, and their pride of place in surgical research is now axiomatic. Onus remains on the researchers to use many available qualitative techniques to study these fascinating 'social' facets of surgery to enrich the surgical literature.

\section{Declarations}

Conflict of Interest The authors declare no competing interests.

\section{References}

1. Gagliardi AR, Dobrow MJ (2011) Paucity of qualitative research in general medical and health services and policy research journals: analysis of publication rates. BMC Health Serv Res 11:268. https://doi.org/10.1186/1472-6963-11-268

2. Greenhalgh T, Annandale E, Ashcroft R, Barlow J, Black N, Bleakley A et al (2016) An open letter to The BMJ editors on qualitative research. BMJ 352:i563. https://doi.org/10.1136/bmj. i563

3. Felton J, Martin O, Kubicki N, Kidd-Romero S, Kavic SM (2021) Understanding the well-being of general surgery residents. Am Surg 87(3):432-436. https://doi.org/10.1177/0003134820951476

4. Srinivasa S, Gurney J, Koea J (2019) Potential consequences of patient complications for surgeon well-being: a systematic review. JAMA Surg 154(5):451-457. https://doi.org/10.1001/jamasurg. 2018.5640

5. Jain G, Sharma D, Agarwal P, Agrawal V, Yadav SK, Tenzin T, et al. 'Second victim' syndrome among the Surgeons from Southeast Asia. Indian J Surg. https://doi.org/10.1007/ s12262-021-02793-3.

6. Sharma D, Cotton M (2021) Editorial: We care for patients but who cares for us? Trop Doct 51(2):141. https://doi.org/10.1177/ 00494755211007280

7. Archer S, Pinto A, Vuik S, Bicknell C, Faiz O, Byrne B et al (2019) Surgery, complications, and quality of life: a longitudinal cohort study exploring the role of psychosocial factors. Ann Surg 270(1):95-101. https://doi.org/10.1097/SLA.0000000000002745

8. Lim WH, Wong C, Jain SR, Ng CH, Tai CH, Devi MK et al (2021) The unspoken reality of gender bias in surgery: a qualitative systematic review. PLoS ONE 16(2):e0246420. https://doi.org/10. 1371/journal.pone. 0246420 
9. Hu YY, Ellis RJ, Hewitt DB, Yang AD, Cheung EO, Moskowitz JT et al (2019) Discrimination, abuse, harassment, and burnout in surgical residency training. N Engl J Med 381(18):1741-1752. https://doi.org/10.1056/NEJMsa1903759

10. Nakkeeran N, Zodpey SP (2012) Qualitative research in applied situations: strategies to ensure rigor and validity. Indian J Public Health 56(1):4-11. https://doi.org/10.4103/0019-557X.96949

11. Barbour RS (2001) Checklists for improving rigour in qualitative research: a case of the tail wagging the dog? BMJ 322(7294):1115-1117. https://doi.org/10.1136/bmj.322.7294. 1115

12. Cristancho SM, Goldszmidt M, Lingard L, Watling C (2018) Qualitative research essentials for medical education. Singapore Med J 59(12):622-627. https://doi.org/10.11622/smedj.2018093

13. Meena JK, Jakhetiya A, Pandey A (2021) Qualitative research in surgical disciplines: need and scope. Indian J Surg 83:3-8. https:// doi.org/10.1007/s12262-020-02280-1

14. O'Brien BC, Harris IB, Beckman TJ, Reed DA, Cook DA (2014) Standards for reporting qualitative research: a synthesis of recommendations. Acad Med 89(9):1245-1251. https://doi.org/10.1097/ ACM.0000000000000388

15. Gallo L, Murphy J, Braga LH, Farrokhyar F, Thoma A (2018) Users' guide to the surgical literature: how to assess a qualitative study. Can J Surg 61(3):208-214. https://doi.org/10.1503/cjs. 013117

16. Mazer L, Sandhu G (2021) The case for social science research in surgery. JAMA Surg 156(5):411-412. https://doi.org/10.1001/ jamasurg.2020.6671
17. Rai R, Dwivedi V, Kumar R, Kumar S (2005) Questionnaire designing. Mammology 1(2):22-26

18. Webster F, Rice K, Christian J, Seemann N, Baxter N, Moulton CA, Cil T (2016) The erasure of gender in academic surgery: a qualitative study. Am J Surg 212(4):559-565. https://doi.org/10. 1016/j.amjsurg.2016.06.006

19. Sprow HN, Hansen NF, Loeb HE, Wight CL, Patterson RH, Vervoort D et al (2021) Gender-based microaggressions in surgery: a scoping review of the global literature. World J Surg 45(5):14091422. https://doi.org/10.1007/s00268-021-05974-z

20. Gerull KM, Wahba BM, Goldin LM, McAllister J, Wright A, Cochran A et al (2020) Representation of women in speaking roles at surgical conferences. Am J Surg 220(1):20-26. https://doi.org/ 10.1016/j.amjsurg.2019.09.004

21. Kottke TE (2011) Medicine is a social science in its very bone and marrow. Mayo Clin Proc 86(10):930-932. https://doi.org/10. 4065/mcp.2011.0444

Publisher's Note Springer Nature remains neutral with regard to jurisdictional claims in published maps and institutional affiliations. 